\title{
Cardiologists' Perception of Wearable Device Data in Patients with Heart Failure
}

\author{
Seysha Mehta ${ }^{7}$, Neil Mehta, MBBS, MS ${ }^{2}$, W. H. Tang, MD², and James Young, $\mathrm{MD}^{2,3}$ \\ 'Dartmouth College, Hanover, NH, USA; ${ }^{2}$ Cleveland Clinic Lerner College of Medicine of Case Western Reserve University, Cleveland, Ohio, USA; \\ ${ }^{3}$ George M. and Linda H. Kaufman Center for Heart Failure Treatment and Recovery, Cleveland Clinic, Cleveland, Ohio, USA.
}

$\mathrm{J}$ Gen Intern Med 35(3):940-1

DOI: $10.1007 / \mathrm{s} 11606-019-05390-\mathrm{z}$

(c) Society of General Internal Medicine 2020

$\mathcal{C}$ ardiologists' Perceptions of Wearable Device Data in Patients with Heart Failure

\section{INTRODUCTION}

The New York Heart Association (NYHA) is used to classify severity of heart failure and estimate prognosis. Its dependence on the physician's opinion regarding what constitutes "ordinary physical activity" or "slight" and "marked" limitation makes it subjective with low concordance between physicians. ${ }^{1,2} \mathrm{Ob}$ jective measures like cardiopulmonary testing are expensive, inconvenient, and time-consuming. Wearable devices like fitness trackers can provide objective $24 / 7$ data and can potentially overcome these limitations. ${ }^{3}$ How such data will be perceived by clinicians is an unanswered and increasingly important and relevant question as many companies are participating in a U.S. Food and Drug Administration pilot program for clearing such devices. ${ }^{4}$ We report the results of a small study to determine the perception of such data by heart failure specialists and its potential impact on the management of such cases.

\section{METHODS}

Consecutive patients with a diagnosis of heart failure coming for a follow-up visit to the heart failure clinic at one tertiary care institution were approached to participate in the IRBapproved study. To be eligible, patients needed to have access to an Internet-enabled smartphone. They were provided a fitness tracker wristband (Microsoft Band), instructed in its use, and asked to wear the band for 2 weeks. The data from the

Prior presentations: An earlier version of the manuscript was presented at the SGIM Mid-West conference in Cleveland, in 2015.

Received February 24, 2019

Revised July 25, 2019

Accepted September 9, 2019

Published online January 2, 2020 wristband was transmitted via their smartphone anonymously to a web portal. At the end of 2 weeks, the data was printed out and shared with the heart failure specialist who saw the patient at the clinic at the initial visit, along with the NYHA assignment from the visit. They were asked to assume that the device was FDA approved and the data was valid. On a selfdeveloped non-validated questionnaire, they indicated whether the data would change their impression of health status and NYHA assignment of the patient. They rated their overall impression of such data for managing patients with heart failure on 3-point scale (not useful, somewhat useful, very useful) and provided optional free-text comments.

\section{RESULTS}

All 23 patients approached enrolled in the study. Six cardiologists reviewed the data for 13 patients that completed the study successfully. Data of 10 other patients seen by the same cardiologists was not available for review due to technical problems or could not be reviewed by the cardiologists within the study window. The mean age of the 23 patients was 69 years, and 10 were female. In 8 of 13 cases, the cardiologists felt that the data would change their perception of the patients' health status, and in 5 cases, they would have changed their original NYHA assignment (Table 1). At the end of the study, 2 reported that overall data from a wearable device would be somewhat useful while 4 reported that it would be very useful in managing patients with heart failure. In the free-text comments, 4 cardiologists reported that they would prefer to have the data available at the time of the patient visit rather than 2 weeks after the visit or in between visits.

\section{DISCUSSION}

This is a small single-center study, but it raises key questions that should be followed up by larger studies. Cardiologists in this study were receptive to the idea of using data from wearable devices to manage patients with heart failure. Cardiologists are aware of the subjective nature of NYHA and thus may be more receptive to objective data to supplement their clinical impressions. Since the NYHA classification can have an impact on decision-making regarding medications and device use, this finding raises the need for research into the 
Table 1 Impact of Fitness Tracker Data on Cardiologists' Opinion of Patients' Health Status and NYHA Assignment

\begin{tabular}{|c|c|c|}
\hline & $\begin{array}{l}\text { Number of } \\
\text { cases }\end{array}$ & Details \\
\hline $\begin{array}{l}\text { Data had an impact on } \\
\text { cardiologists' clinical opinion } \\
\text { of health status from visit }\end{array}$ & $8 / 13$ & $\begin{array}{l}2 \text { worse than } \\
\text { estimated at visit } \\
3 \text { better than } \\
\text { estimated at visit } \\
2 \text { confirmed estimates } \\
\text { at visit } \\
1 \text { sleep pattern helped } \\
\text { understand health } \\
\text { status }\end{array}$ \\
\hline $\begin{array}{l}\text { Data would change NYHA } \\
\text { assignment from visit }\end{array}$ & $5 / 13$ & $\begin{array}{l}2 \text { from class III to } \\
\text { class II } \\
1 \text { from class II to } \\
\text { class I } \\
2 \text { from class II to } \\
\text { class III }\end{array}$ \\
\hline
\end{tabular}

accuracy of fitness trackers and the role of wearable device data use for prognosis and clinical decision making in heart failure. Cardiologists prefer to integrate this data review process into clinic visits. This integration will be increasingly difficult as the amount of data increases, and will require the development of data analysis and visualization tools to support the clinicians at and in-between clinic visits. ${ }^{5}$ As we design population health models, it will be necessary to keep this in mind to get maximum benefit from such data from always-on wearable devices.

Patients may face technical challenges when using these devices and may not have access to the Internet or smartphones. These issues need to be considered to reduce the impact of the digital divide on health inequities.

Corresponding Author: Neil Mehta, MBBS, MS; Cleveland Clinic Lerner College of Medicine of Case Western Reserve University, Cleveland, Ohio, USA (e-mail: mehtan@ccf.org).
Funding Information The work was supported by an unrestricted grant from Microsoft Corporation that donated 20 wristbands for the study. The production and sale of these devices has since been discontinued.

\section{Compliance with Ethical Standards:}

Conflict of Interest: The authors have disclosed that Dr. NM owns stock in Microsoft and receives royalties from licensing a software program. Dr. JY and Dr. WHT serve as consultants for various device and biopharmaceutical companies, and both have received several NIH grants. None of these pose potential conflicts of interest for this study (Microsoft has since discontinued its wearable device product). All remaining authors declare that they do not have a conflict of interest.

\section{REFERENCES}

1. Raphael C, Briscoe C, Davies J, et al. Limitations of the New York Heart Association functional classification system and self-reported walking distances in chronic heart failure. Heart Br Card Soc. 2007;93(4):476-82.

2. Goldman L, Hashimoto B, Cook EF, Loscalzo A. Comparative reproducibility and validity of systems for assessing cardiovascular functional class: advantages of a new specific activity scale. Circulation. 1981;64(6):122734.

3. Jehn M, Schmidt-Trucksäss A, Schuster T, et al. Daily walking performance as an independent predictor of advanced heart failure: Prediction of exercise capacity in chronic heart failure. Am Heart J. 2009;157(2):292-8.

4. U.S. Food and Drug Administration. FDA selects participants for new digital health software precertification pilot program. Available at: https:// www.fda.gov/newsevents/newsroom/pressannouncements/ucm577480. htm. Accessed August 18, 2019.

5. Faiola AJ, Srinivas P, Doebbeling BN. A ubiquitous situation-aware data visualization dashboard to reduce ICU clinician cognitive load. In: 2015 17th International Conference on E-health Networking, Application Services (HealthCom). 2015. p. 439-42. Available at: https://ieeexplore.ieee. org/document/7454540. Accessed August 18, 2019.

Publisher's Note Springer Nature remains neutral with regard to jurisdictional claims in published maps and institutional affiliations. 